\title{
Criptococosis pulmonar enmascarada por tuberculosis miliar. Coinfección pulmonar e implicancias diagnósticas y terapéuticas en pacientes con VIH
}

\section{Pulmonary Cryptococcosis masked by miliary tuberculosis. Pulmonary coinfection and diagnostic \& therapy implications in HIV-infected patients}

Correspondencia Julio Maquera-Afaray maquera.afaray.julio@gmail.com

Recibido: 19/09/2016 Aprobado: 12/10/2016

Citar como: Maquera-Afaray J, Olazabal-Chambilla DY, Larico-Calla G, Díaz-Quiquia VE. Criptococosis pulmonar enmascarada por tuberculosis miliar. Coinfección pulmonar e implicancias diagnósticas y terapéuticas en pacientes con VIH. Acta Med Peru. 2016:33(4):313-6
Julio Maquera-Afaray ${ }^{1,2}$, Derly Yerson Olazabal-Chambilla³, Gabriel LaricoCalla $^{3}$, Vasti Evelyn Díaz-Quiquia ${ }^{3}$

1 Unidad de Infectología, Hospital Nacional Guillermo Almenara Irigoyen. Lima, Perú.

2 Universidad Peruana Cayetano Heredia. Lima, Perú.

3 Universidad Peruana Unión. Lima, Perú.

\section{RESUMEN}

La criptococosis es una micosis asociada frecuentemente al Virus de Inmunodeficiencia Humana $(\mathrm{VIH})$ que afecta principalmente el sistema nervioso central seguido por el compromiso pulmonar. Reportamos el caso de una paciente mujer de 53 años de edad con inmunocompromiso por infección con VIH quien presentó una coinfección pulmonar (criptococosis y tuberculosis). En la tomografía torácica se le encontraron lesiones micronodulares y nodulares, la baciloscopía de esputo fue positiva. Recibió tratamiento antituberculoso, pero solo hubo mejoría parcial del cuadro. Ante la sospecha de criptococosis pulmonar se solicitó antígeno criptocócico sérico cuyo resultado fue positivo. Se confirmó el diagnóstico mediante biopsia de nódulo pulmonar guiada por tomografía. El paciente recibió tratamiento antifúngico y tuvo una evolución favorable. Es importante reconocer a la criptococosis no solo como una entidad que afecta el sistema nervioso central y conocer sus manifestaciones clínicas como imagenológicas más frecuentes que nos permitan diagnosticarlo y diferenciarlo de otras patologías pulmonares.

Palabras clave: Criptococosis; Tuberculosis; VIH (fuente: DeCS BIREME).

\section{ABSTRACT}

Cryptococcal disease is a mycosis frequently associated with HIV infection, which mainly affects the central nervous system, followed by lung involvement. We report a case of an HIVinfected 53-year-old female patient, who developed a pulmonary co-infection (cryptococcosis and tuberculosis). The thoracic CT scan revealed micronodular and nodular lesions, and AFB were found in the sputum. Antituberculous therapy was started, but there was only partial improvement. Since pulmonary cryptococcosis was suspected, a serum cryptococcal antigen test was requested, which turned out to be positive. The diagnosis of the fungal disease was confirmed with a CT-guided biopsy of a pulmonary nodule. The patient received antifungal therapy and she did well. It is important to consider cryptococcosis not only as a condition affecting the central nervous system, but also to recognize its different and most frequent clinical and image manifestations which may allow us to timely diagnose it and differentiate it from other pulmonary conditions.

Keywords: Cryptococcosis; Tuberculosis; HIV (source: MeSH NLM). 


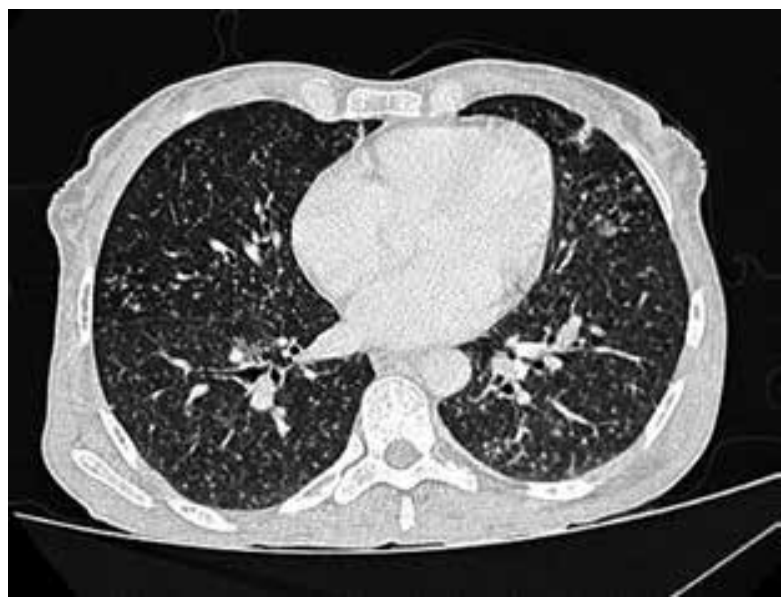

Figura 1. Tomografía axial computarizada de tórax donde se evidencia patrón miliar bilateral, e insinúa discreto infiltrado en base de hemitórax izquierdo.

\section{INTRODUCCIÓN}

La criptococosis es una enfermedad de distribución global con una morbilidad y mortalidad significativa, ocasionada por miembros del complejo Cryptococcus neoformans/Cryptococcus gattii, agrupadas en dos especies relacionadas: $C$. neoformans, conformadas por las variedades grubii (serotipo A) y neoformans (serotipo D) y un híbrido serotipo $A D ; y C$. gattii, con los serotipos $B$ y ${ }^{[1,2]}$. La criptococosis ha adquirido mayor importancia en pacientes inmunosuprimidos por la infección por el virus de inmunodeficiencia humana (VIH); sin embargo, también existen diversas condiciones que predisponen a la infección criptococósica como las enfermedades linfoproliferativas, autoinmunes, metabólicas, otras relacionadas al uso de corticoides y terapias biológicas, e incluso puede afectar a personas inmunocompetentes ${ }^{[3,4]}$.

En la criptococosis el compromiso meníngeo es más frecuente, seguido por la afectación pulmonar; aunque la infección resulta por inhalación del organismo de una fuente medioambiental y la posterior diseminación por vía hematógena al sistema nervioso central ${ }^{[5]}$. La mayoría de estudios en criptococosis pulmonar se han desarrollado en pacientes inmunocomprometidos, y la comprensión de esta enfermedad está limitada a ciertas manifestaciones clínicas y radiológicas necesarias para diferenciarla de otras patologías infecciosas como la tuberculosis y no infecciosas como el cáncer pulmonar ${ }^{[6]}$.

Por tanto, presentamos un caso de coinfección pulmonar, criptococosis y tuberculosis, en una paciente inmunocomprometida con infección VIH con la finalidad de mostrar ciertas características e implicancias diagnósticas y terapéuticas relevantes que permitan identificarlas, diferenciarlas y manejarlas apropiadamente evitando demoras tanto en diagnóstico como tratamiento que repercutan negativamente sobre el pronóstico del paciente.

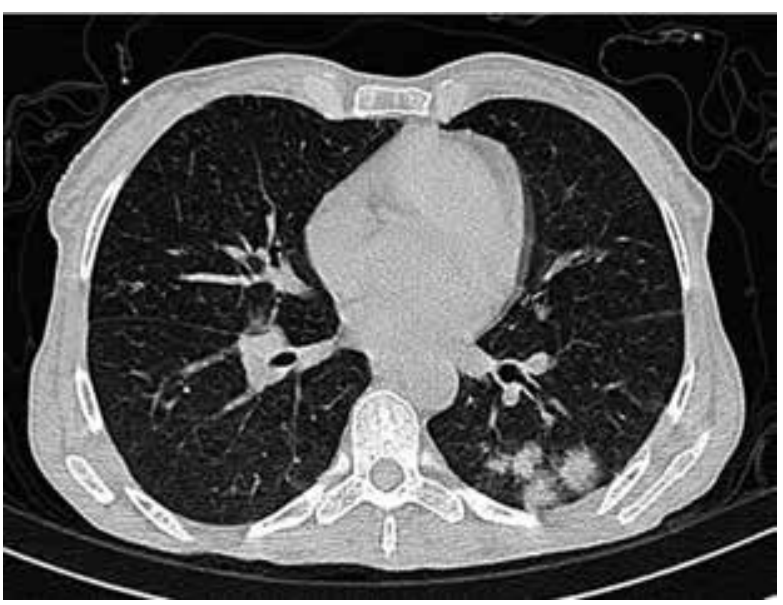

Figura 2. Tomografía axial computarizada de tórax donde se evidencia disminución del patrón miliar pulmonar pero presencia de marcados infiltrados nodulares a predominio basal izquierdo.

\section{REPORTE DE CASO}

Mujer de 53 años, natural y procedente de Lima, con diagnóstico reciente de infección $\mathrm{VIH}$, quien acude a consulta por cuadro clínico de aproximadamente tres semanas de evolución caracterizado por tos productiva, dolor torácico y baja de peso. Al examen físico general se identificó un mal estado nutricional y presencia de muguet oral; al examen físico preferencial de tórax se encontraron estertores (crepitantes) en ambas bases pulmonares, a nivel neurológico no se evidenció signo meníngeo alguno.

Los resultados de los exámenes de laboratorio más relevantes fueron: anemia leve, recuento de células $\mathrm{CD}_{4}+246 \mathrm{cel} / \mu \mathrm{L}$, carga viral para VIH 11000000 copias $/ \mathrm{mL}$, serología para hepatitis virales $B$ y $C$ negativas, HTLV 1-2 negativa y baciloscopía de esputo positiva. En la tomografía tórax (Figura 1) se evidenció un patrón miliar bilateral, diagnosticándose tuberculosis miliar e iniciándose tratamiento antituberculoso. Posteriormente, tras presentar leve mejoría clínica, se solicitó una tomografía de control que mostró una mejoría del patrón miliar, y que permitió ver lesiones nodulares múltiples en base izquierda previamente no descritas (Figura 2).

Ante este hallazgo se ampliaron estudios, entre ellos el dosaje sérico de antígeno criptocócico $(\mathrm{AgCr})$ que dió positivo; se decidió realizar el estudio de líquido cefalorraquídeo (LCR) cuyo resultado (tinta china, $\mathrm{AgCr}$, y cultivo para hongos en LCR) fue negativo para criptococosis meníngea. Se realizó biopsia guiada por tomografía de los nódulos pulmonares que dio resultado positivo para Cryptococcus sp., confirmando el diagnóstico de criptococosis pulmonar. Se inició el tratamiento con anfotericina $B$ desoxicolato por dos semanas, y luego continuar con fluconazol vía oral. La paciente evolucionó de manera favorable y fue dada de alta hospitalaria. 


\section{DISCUSIÓN}

La criptococosis constituye una micosis grave asociada con mayor frecuencia al VIH, como una complicación que afecta principalmente el sistema nervioso central seguido por el compromiso pulmonar, cutáneo y ocular ${ }^{[4]}$. Aunque la vía respiratoria es la puerta de entrada de la infección, la mayor parte ocurre solo como una neumonitis primaria subclínica habiendo sido descrita menos frecuentemente en pacientes $\mathrm{VIH}$ comparado con grupos no $\mathrm{VIH}$; sin embargo, el compromiso pulmonar en pacientes $\mathrm{VIH}$ con diagnóstico de meningitis criptococósica varía entre 10 a $55 \%$ de $\operatorname{casos}^{[3,7]}$; contrariamente a lo descrito, nuestra paciente presentó sintomatología respiratoria, pero debemos destacar que tuvo coinfección pulmonar por Mycobacterium tuberculosis, y tampoco presentó compromiso meníngeo.

La criptococosis pulmonar ocasionalmente ocurre en coinfección con otros patógenos pulmonares, entre los que se han reportado tuberculosis, nocardiosis y equinococosis ${ }^{[4]}$. Algunos autores consideran esta enfermedad como subdiagnosticada, e incluso tratada erróneamente confundiéndola con otra entidad nosológica, principalmente la tuberculosis pulmonar, y resaltan la importancia considerar dentro de los diagnósticos alternativos a la criptococosis pulmonar entre otras causas (neumonía por Pneumocystis jirovecii o Cytomegalovirus, que también fueron descartadas en nuestra paciente); más aún en países donde la tuberculosis es endémica y pudiese inducir equívocamente el comienzo de tratamiento anti-tuberculoso en pacientes con factores de riesgo pero sin confirmación bacteriológica, y peor aún progresión a esquemas de terapia para tuberculosis drogoresistente cuando no presentan respuesta favorable, prolongando tratamientos erróneos que repercutirán negativamente sobre el pronóstico del paciente ${ }^{[8]}$. Al respecto, cabe mencionar que la coinfección tuberculosis-VIH ha incrementado significativamente el riesgo de morbilidad y mortalidad, inclusive la tuberculosis es la principal causa de admisión hospitalaria en personas viviendo con $\mathrm{VIH}^{[9]}$.

Las infecciones oportunistas en pacientes VIH se relacionan fundamentalmente con la enfermedad avanzada e inmunosupresión severa; la criptococosis generalmente se presenta con recuentos de $C_{4}+$ menores de 100 células $/ \mu \mathrm{L}$, mientras que la tuberculosis miliar es más frecuente en pacientes $\mathrm{VIH}$ con recuento de $\mathrm{CD}_{4}+<200$ células $/ \mu \mathrm{L}^{[10,11]}$. En nuestro caso, aunque la paciente presentó un recuento de $\mathrm{CD}_{4}+$ de 246 células/ $\mu \mathrm{L}$, este dato no era suficiente para afirmar que no había riesgo de infección y desarrollo de estas enfermedades, más con los hallazgos sugestivos encontrados en los estudios por imágenes.

El diagnóstico definitivo de criptococosis pulmonar idealmente requiere la identificación del organismo obtenido de un tejido estéril a través de una biopsia pulmonar; no obstante, en pacientes con VIH el síndrome clínico compatible y asilamiento microbiológico de $C$. neoformans en muestra respiratoria es considerado, por algunos expertos en la práctica, como suficiente para iniciar el tratamiento antifúngico ${ }^{[12]}$. Actualmente, existe un biomarcador fúngico que detecta a antígenos criptococósicos y permite un diagnóstico y tratamiento oportunos e incluso anticipados, sobre todo en pacientes $\mathrm{VIH}$ con recuento de $\mathrm{CD}_{4}+$ menor 100 células/ $\mu L^{[13,14]}$. Además, la presencia de lesiones en imágenes de tórax, como la presencia de nódulos pulmonares únicos o múltiples constituyen el signo más frecuente y sugestivo de criptococosis pulmonar, pero también se han reportado casos de criptococosis pulmonar con patrón miliar ${ }^{[15,16]}$. Cabe resaltar que en el caso la coinfección con tuberculosis dificultó la sospecha diagnóstica debido a que la tuberculosis puede semejar distintos patrones radiológicos.

Respecto al tratamiento, el objetivo a alcanzar en criptococosis pulmonar es el control de las manifestaciones clínicas, resolución de los hallazgos anormales imagenológicos, negativización de cultivos fúngicos de muestras de respiratoria y evitar la diseminación al sistema nervioso; el esquema terapéutico a emplear dependerá del grado de compromiso pulmonar, siendo requerido en casos graves el uso de anfotericina $B$ como en la criptococosis meníngea, pero en casos leves a moderados, con ausencia de infiltrados pulmonares difusos y sin compromiso meníngeo y/o diseminación, podría solo requerir fluconazol como medicamento de elección ${ }^{[7]]}$.

En conclusión, es importante reconocer a la criptococosis no solo como una entidad que afecta el sistema nervioso central, que el compromiso pulmonar por $C$. neoformans en pacientes con VIH puede estar subdiagnosticado y/o enmascarado por otras patologías pulmonares más frecuentes como la tuberculosis, agravando el pronóstico del paciente. Por tanto, se requiere de una alta sospecha clínica, además del empleo de otras herramientas diagnósticas útiles como el antígeno criptocócico y/o presencia de lesiones nodulares en estudios imagenológicos que permitan plantearlo en el diagnóstico diferencial, direccione un oportuno y apropiado diagnóstico microbiológico y tratamiento antifúngico y que finalmente disminuya la morbilidad y mortalidad atribuida a esta infección fúngica cosmopolita.

Fuente de financiamiento: El presente estudio ha sido autofinanciado por los autores.

Declaración de conflictos de intereses: Los autores declaran no tener conflictos de interés con respecto a la publicación del presente estudio.

\section{REFERENCIAS BIBLIOGRÁFICAS}

1. Tello M, Gutiérrez E, BéjarV, Galarza C, Ramos W, Ortega-Loayza A. Criptococosis. Rev Méd Risaralda. 2013;19(2):147-53.

2. Escandon P, Montilla A. Molecular typing of the Cryptococcus neoformans/Cryptococcus gattii species complex. Infectio. 2010;14(S2):S127-30.

3. Huston SM, Mody $\mathrm{CH}$. Cryptococcosis: an emerging respiratory mycosis. Clin Chest Med. 2009;30(2):253-64

4. Perfect JR. Cryptococcus neoformans. In: Mandell GL, Bennett JE, Dolin R. Mandell, Douglas, and Bennett's principles and practice of infectious diseases. Philadelphia: Churchill Livingstone Elsevier; 2010. p. 3287-304. 
5. Chang CC, SorrellTC, Chen SC. Pulmonary Cryptococcosis. Semin Respir Crit Care Med. 2015;36(5):681-91.

6. Xie $X, X \cup B, Y \cup C, C$ en $M, Y a o D, X \cup X$, et al. Clinical analysis of pulmonary cryptococcosis in non-HIV patients in south China. Int J Clin Exp Med. 2015;8(3):3114-9.

7. Jarvis JN, Harrison TS. Pulmonary cryptococcosis. Semin Respir Crit Care Med. 2008;29(2):141-50.

8. Jarvis JN, Wainwright $H$, Harrison TS, Rebe K, Meintjes G. Pulmonary cryptococcosis misdiagnosed as smear-negative pulmonary tuberculosis with fatal consequences. Int J Infect Dis. 2010;14(3):e310-2.

9. Ford N, Shubber Z, Meintjes G, Grinsztejn B, Eholie S, Mills EJ, et al. Causes of hospital admission among people living with HIV worldwide: a systematic review and meta-analysis. Lancet HIV. 2015;2(10): $4338-44$.

10. Castro MR, Córdova H. Características clínicas y laboratoriales de la coinfeccion VIH-SIDA y criptococosis meningea en el Hospital Clínico Viedma de Cochabamba, Bolivia. Gac Med Bol. 2014;37(2):64-7.

11. Sharma SK, Mohan A, Sharma A. Challenges in the diagnosis \& treatment of military tuberculosis. Indian J Med Res. 2012;135(5):703-30
12. YooSD, WorodriaW, Davis JL, Cattamanchi A, de Boon S, Kyeyune $\mathrm{R}$, et al. The prevalence and clinical course of HIV-associated pulmonary cryptococcosis in Uganda. J Acquir Immune Defic Syndr. 2010;54(3):269-74.

13. Andama AO, den Boon S, Meya D, Cattamanchi A, Worodria $\mathrm{W}$, Davis JL, et al. Prevalence and Outcomes of Cryptococcal Antigenemia in HIV-Seropositive Patients Hospitalized for Suspected Tuberculosis in Uganda. J Acquir Immune Defic Syndr. 2013;63(2):189-94.

14. Reyes SZ, Zambrano LI, Palou EY. Complicaciones temibles en un paciente con VIH/SIDA: criptococosis, tuberculosis miliar, meningoencefalitis. Rev Fac Cienc Med. 2012;9(1):53-6.

15. Chang WC, Tzao C, Hsu HH, Lee SC, Huang KL, Tung HJ, et al. Pulmonary cryptococcosis: comparison of clinical and radiographic characteristics in immunocompetent and immunocompromised patients. Chest. 2006;129(2):333-40.

16. Rigby AL, Glanville AR. Miliary pulmonary criptococcosis in an HIVpositive patient. Am J Respir Crit Care Med. 2012;186(2):200-1.

17. Perfect JR, Dismukes WE, Dromer F, Goldman DL, Graybill JR, Hamill RJ, et al. Clinical Practice Guidelines for the Management of Cryptococcal Disease: 2010 Update by the Infectious Diseases Society of America. Clin Infect Dis. 2010;50(3):291-322.

\section{Las ediciones anteriores de Acta Médica Peruana están disponibles en:}

\section{www.scielo.org.pe}

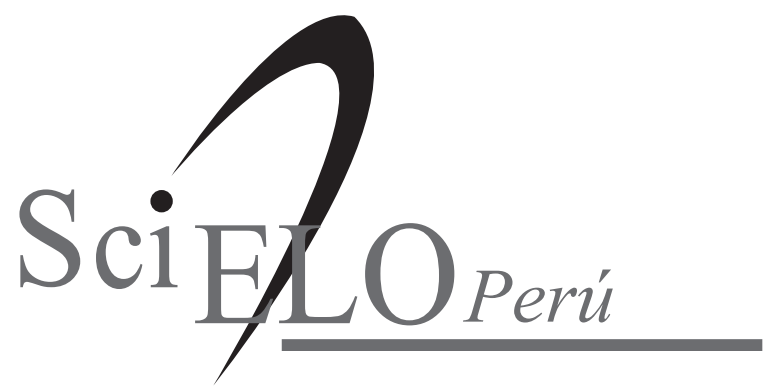

